\title{
Relationship between selected hormonal and metabolic parameters at birth and blood pressure during pre-adolescence
}

\author{
Anibal Nieto, MD, PhD ${ }^{1}$, Julián A. Herrera, MD², José Villar MD³,

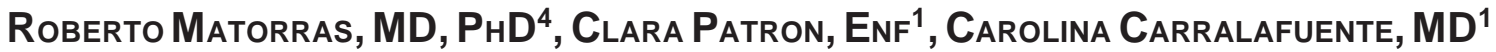

\section{ABSTRACT}

Objective: The aim of the present study was to evaluate the relationship between selected hormonal parameters (at birth and at age 8 years) and blood pressure levels at pre-adolescence in a cohort of intrauterine growth retarded (IUGR) and normal birth weight infants (NBW).

Methods: A cohort study from early pregnancy to childhood was performed. Seventy-six fetuses/children were evaluated between 1995 and 2004. Cord blood samples were taken at birth and several hormonal and metabolic parameters evaluated. Sixty-four children of the original cohort were available for blood sampling, blood pressure and anthropometric measures at a mean age of 8 years. 27 (42.2\%) were IUGR and 37 (57.8\%) were NBW. Multiple regression analyses were conducted with cord blood levels of hormonal and metabolic parameters at birth and at 8 years as independent variables and children's blood pressure as dependent variable adjusted by IUGR status, gender, Body Mass Index and age of the child at the time of blood pressure evaluation.

Results: The maternal age(26.6 $\pm 5.8 v s$ 26.9 \pm 5.8 years old) and the gestational age at birth (39.1 \pm 1.4 vs $39.6 \pm 1.3$ weeks) were similar between the groups. IUGR children were shorter $(1.28 \pm 0.09 \mathrm{~m}$ vs $1.33 \pm 0.09 \mathrm{~m}, \mathrm{p}=0.04)$. Growth hormone levels (GH) at birth were negatively associated with systolic blood pressure at 8 years of age (regression coefficients for umbilical cord blood levels: -0.9 , 95\% CI -2.03 to $0.04 \mathrm{mg} / \mathrm{ml}, \mathrm{p}=0.04$ ).

Conclusion: The alterations on blood pressure can begin in fetal life were levels of GH could have an important role.

Keywords: Restriction of intrauterine growth; Fetal growth hormone; Pre-adolescence growth; Blood pressure.

Relación entre parámetros endocrino-metabólicos al nacimiento y la presión arterial durante la pre-adolescencia

\section{RESUMEN}

Objetivo: Evaluar la relación entre parámetros hormonales seleccionados (al nacimiento y a los 8 años de edad) y los niveles de presión arterial a los 8 años de edad en una cohorte de niños con restricción en el crecimiento intrauterino (RCIU) y con peso normal al nacimiento (PNN).

Material y métodos: Se realizó un estudio de cohortes desde el inicio del embarazo hasta la infancia(1995-2004). Se tomaron muestras de sangre de cordón umbilical al nacimiento y a los 8 años para evaluar parámetros endocrino-metabólicos seleccionados (variable independiente) y la presión arterial a los 8 años de edad (variable dependiente). Se evaluaron 64 niños de la cohorte original; 27 (42.2\%) casos pertenecían al grupo de RCIU y 37 (57.8\%) al grupo con PNN. El análisis multivariado se ajustó por RCIU, género, índice de masa corporal y edad del niño en el momento de medir la presión arterial.

Resultados: La edad de las madres (26.6 \pm 5.8 vs 26.9 \pm 5.8 años) y la edad gestacional al parto (39.1 \pm 1.4 vs 39.6 \pm 1.3 semanas) fueron similares entre los grupos. Los niños de 8 años que nacieron con RCIU fueron más bajos (1.28 $\pm 0.09 \mathrm{~m}$ vs $1.33 \pm 0.09$ $\mathrm{m}, \mathrm{p}=0.04)$. Los niveles de hormona de crecimiento $(\mathrm{GH})$ al nacimiento fueron asociados negativamente con la presión arterial

1. Associate Professor, Department of Obstetrics and Gynaecology, Hospital Universitario Príncipe de Asturias, Universidad de Alcalá, Alcalá de Henares, Madrid, Spain. e-mail: anibal.nieto@uah.es clmanzanara@hotmail.com

2. Emeritus Head Professor, Department of Family Medicine, Universidad del Valle, Cali, Colombia. e-mail:herreja@univalle.edu.co

3. UNDP/UNFPA/WHO/World Bank Special Programme of Research, Development and Research Training in Human Reproduction, Department of Reproductive Health and Research, World Health Organization, Geneva. e-mail:villarj@who.int

4. Hospital de Cruces, Baracaldo, University del País Vasco, Vizcaya, Spain.

Recibido para publicación enero 18, 2008 Aceptado para publicación enero 15, 2009 
sistólica del niño (coeficiente de regresión: -0.9, 95\% CI -2.03 a $0.04 \mathrm{mg} / \mathrm{ml}, \mathrm{p}=0.04)$.

Conclusión: Las alteraciones de la presión arterial pueden comenzar desde la vida fetal y los niveles de GH fetal pueden jugar un papel importante.

Palabras clave: Restricción de crecimiento intrauterino; Niveles hormonales fetales; Crecimiento en la preadolescencia; Presión arterial.

The possibility of an intrauterine programming of blood pressure later on in life and the risk of various chronic diseases attracts considerable interest. This hypothesis is supported by a growing number of observational and experimental studies ${ }^{1}$ although concerns have been raised on some methodological limitations of these studies, the different outcomes selected and the inconsistencies of the results ${ }^{2}$. Furthermore, most studies used birth weight and other anthropometric measures at birth as proxy indicators for intrauterine growth impairment without providing physiological or metabolic explanatory data for the possible mechanisms underlining these associations. It was observed ${ }^{3}$ endocrinological alterations associated with intrauterine growth restriction, particularly higher growth hormone values in cord blood at birth, perhaps as a functional compensatory mechanism of the hypothalamic-pituitary axis to foetal growth restriction ${ }^{3}$. As a follow-up to these results, we have conducted the present prospective study specifically designed to evaluate the following «a-priori» question: is there a relationship between selected hormonal and metabolic parameters at birth and at 8 years of age with blood pressure during pre-adolescence? Also, we have evaluated the differences in postnatal growth and blood pressure between intrauterine growth restriction(IUGR) and normal birth weight (NBW) children.

\section{MATERIAL AND METHODS}

Original cohort. This is a follow-up pilot study of a cohort of infants born between 1995 and 2004 at the Department of Obstetrics and Gynaecology, Principe de Asturias University Hospital, Alcalá de Henares, Madrid, Spain. The original population included 94 singleton pregnancies, without congenital malformations and/or chromosomal abnormalities that delivered at term ( $>37$ weeks to $<42$ weeks of gestation). This study was specifically conducted to explore the association between newborn anthropometric and endocrine parameters, the present follow-up represents a natural extension of this initial research ${ }^{3}$. Gestational age was calculated using the date of the last menstrual period and first trimester ultrasound measures and corroborated by physical examination of the newborn. In case of disagreement of more than two weeks among the different methods, early ultrasound dating was used. There were 47 fetus suspected at ultrasound examination to have intrauterine growth restriction(IUGR), of whom 31 actually had birth weight at or below the tenth percentile of a local standard confirming the diagnosis ${ }^{3}$ they constitute the IUGR population. Forty-seven newborns were identified immediately after birth of each suspected IUGR and selected as controls, if they had birth weight $>10$ th percentile of the same local standard ${ }^{3}$; they are the normal birth weight population. There were two eligible control newborns that could not be included because cord blood collection was not possible. Therefore the initial study population includes 31 confirmed IUGR and 45 NBW infants ${ }^{3}$.

Follow-up. Between 1 November 2003 and 30 September 2004 (on average 8 years postpartum) all the 76 families of the newborns originally studied were identified from hospital records and contacts were attempted to their last known address; those that could not be located were contacted using the social security number registered in the medical record and the new address reported to the regional health care authority. One IUGR child died at one year of age of meningitis and 3 IUGR and 8 NBW refused to participate. Thus, we were able to locate 64 children from the original cohort (84\%) and assessed during childhood 27 IUGRs (87\%) and $37 \mathrm{NBW}$ infants (82\%).

Blood extractions, physical examinations and a brief pediatric history were conducted at the hospital between 8 and 9 am. Height was measured using custom-made stadiometers with the children wearing no shoes. Weight was measured using calibrated scale with children in light clothing. Skinfold measurement was obtained at the triceps and subscapular sites with «Holtain caliper, UK». All anthropometric measurements were taken twice. Body Mass Index (BMI) was calculated as weight in kilograms divided by the square of height in meters. Examinations of the children were conducted at a mean age of 8.0 (SD 1.1) years in the IUGR group and 
8.4 (SD 1.0) years in the normal birth weight group.

Systolic and diastolic blood pressure were measured in the child's right arm, after a period of rest, in a seated position with the arm resting on a supportive surface at the heart level, by only one examiner, a nurse-midwife specifically trained for this study. She was blinded to the birth characteristics of the children and to the specific hypotheses of the study. Two consecutive measures of systolic and diastolic blood pressure (Korotkoff V sound; disappearance of sounds) were taken five minutes apart using a standard mercury sphygmomanometer with a cuff bladder size of $15 \mathrm{~cm}$ by $9 \mathrm{~cm}$ following the recommended criteria ${ }^{4}$. The average of the two blood pressure recordings was considered as the blood pressure for the analyses.

IUGR and NBW children were compared at a mean age of 8 years using standard statistical methods for mean and proportions. Multiple linear regression analyses were conducted using as dependent variable blood pressure during childhood and, as independent variables, the hormonal and metabolic values measured in cord blood and blood samples at assessment. Adjustments were made by gender, fetal growth category (IUGR versus NBW), gestational age at birth, maternal smoking and educational level, as well as children's age and body mass index (BMI) at assessment, as possible confounding variables. We used the Statview II statistical package in all analyses.

This study was approved following the routine review process of the Department of Obstetrics and Gynaecology of the Principe de Asturias University Hospital, Alcalá de Henares, Madrid, Spain and the Institutional Ethical Committee. Mothers provided informed consent for the blood pressure measurements and blood extractions of their children.

Laboratory methods. Arterial blood umbilical cord samples were taken immediately after birth, at umbilical cord clamping but before cutting the cord. Each sample of $20 \mathrm{ml}$ was processed in duplicate, centrifuged and stored at $-40^{\circ} \mathrm{C}$ until assay. At age 8 years, fasting blood samples were collected by venoclisis of the cubital vein. $15 \mathrm{ml}$ of blood were extracted and processed in the same as the umbilical cord blood samples, the same serum parameters as at birth were determined. The laboratory team was blind to clinical condition of the patient.

We measured in these samples selected hormonal and metabolic parameters as growth hormone (GH), insulin growth factor-I (IGF-I), cortisol, insulin, tirostimuline hormone(TSH), prolactin, glucose, cholesterol, triglycerides, albumin and magnesium. We did not measure IGF-I binding protein independently. IGF-I was measured by radio immunoassay (Lab. Systems, USA), insulin and GH by colorimetric enzymoimmunoassay (Medgenix Diagnostics, Belgium) ${ }^{5}$. For insulin intra-assay coefficient of variation of 3.6\%, inter-assay coefficient of variation of $7.1 \%$ for $\mathrm{GH}$; TSH by fluorometric assay (Baxter S.A., USA) ${ }^{6}$; cortisol by fluorescence polarization immunofluorometric assay (Abbott SA, USA), intra-assay coefficient of variation of $4.1 \%$, inter-assay coefficient of variation of $7.2 \%$; prolactin by a immunofluorometric assay (Pharmacia LKB-Wallac, Finland), intra-assay coefficient of variation of 3.3\%, inter-assay coefficient of variation of $4 \%$. The metabolic parameters (insulin and cholesterol levels) were measured with the Hitachi 717 autoanalyzer, Tokyo, Japan. A significant statistical difference was considered with a p value lower than 0.05 .

\section{RESULTS}

The maternal age was similar between the groups (Table 1). The weeks of gestational age at birth and the height of the newborns were similar between the groups (Table 1). The mean of the birthweight and the neonatal ponderal index was different between the groups (Table 1). Tables 2 and 3 show data for hormonal and metabolic parameters at birth and at 8 years of age for the children included classified as intrauterine growth restriction (IUGR) and normal birth weight (NBW). At birth IUGR children had higher cord blood growth hormone levels but lower insulin, thyroid stimulating hormone and cholesterol values (Table 2). IGF-I intra-assay coefficient of variation of $4.2 \%$, inter-assay coefficient of variation of $5.1 \%$. We found no statistical significant differences between groups of these parameters at age of 8 years although growth hormone levels remained higher in the IUGR group (Table 3).

At 8 years of age IUGR children were shorter, tended to be lighter but had similar BMI than the NBW group (Table 4). At this age, the mean systolic and diastolic blood pressure in the IUGR group was lower as compared with the NBW group without statistical difference. IUGR children have mean systolic and diastolic blood pressure $3.64 \mathrm{mmHg}$ and $2.63 \mathrm{mmHg}$ 
Table 1

Perinatal characteristics at birth of 64 children. Hospital Universitario Príncipe de Asturias, Alcalá de Henares, Madrid, Spain. 1995

\begin{tabular}{|c|c|c|c|}
\hline Parameter & $\begin{array}{l}\text { Intrauterine growth restriction } \\
\qquad(\mathrm{N}=27)\end{array}$ & $\begin{array}{l}\text { Normal birth weight } \\
\qquad(\mathrm{N}=37)\end{array}$ & $p$ \\
\hline Gestation age (wk.) (Mean/SD) & $39.1 \pm 1.4$ & $39.6 \pm 1.3$ & 0.09 \\
\hline Maternal age (years) (Mean/SD) & $26.6 \pm 5.8$ & $26.9 \pm 5.8$ & 0.62 \\
\hline Weight (at birth (g) (Mean/SD) & $2487 \pm 221$ & $3269 \pm 345$ & $<0.01$ \\
\hline Height (at birth) (cm) (Mean/SD) & $48.09 \pm 2.31$ & $48.15 \pm 2.16$ & 0.87 \\
\hline Neonatal ponderal index & $2.44 \pm 0.33$ & $2.70 \pm 0.23$ & $<0.01$ \\
\hline \multicolumn{4}{|c|}{$\begin{array}{l}\text { Hormonal and metabolic characteristics at birth of } 64 \text { children. } \\
\text { Hospital Universitario Príncipe de Asturias, Alcalá de Henares, Madrid, Spain. } 1995\end{array}$} \\
\hline Parameter & $\begin{array}{l}\text { Intrauterine growth restriction } \\
\qquad(\mathrm{N}=27)\end{array}$ & $\begin{array}{l}\text { Normal birth weight } \\
\qquad(\mathrm{N}=37)\end{array}$ & $p$ \\
\hline Growth hormone (ng/ml) & $25.8(3.3) *$ & $15.7(1.5)$ & 0.0008 \\
\hline Insulin-like growth factor I (mU/ml) & $0.6(0.09)$ & $0.7(0.06)$ & 0.3 \\
\hline Cortisol (ug/dl) & $15.9(1.9)$ & $17.6(1.8)$ & 0.2 \\
\hline Insulin (U/ml) & $2.5(0.6)$ & $5.2(0.9)$ & 0.05 \\
\hline Thyroid stimulating hormone(uU/ml) & $9.2(0.8)$ & $14.3(1.7)$ & 0.03 \\
\hline Prolactin $(\mathrm{ng} / \mathrm{ml})$ & $226.9(12.4)$ & $208.2(12.3)$ & 0.2 \\
\hline Glucose (mg/dl) & $86.0(5.1)$ & $96.0(3.9)$ & 0.13 \\
\hline Cholesterol (mg/dl) & $60.5(2.2)$ & $70.3(2.6)$ & 0.01 \\
\hline Triglycerides (mg/dl) & $35.6(2.8)$ & $37.3(1.9)$ & 0.29 \\
\hline Albumin $(g / d l)$ & $3.9(0.05)$ & $4.2(0.04)$ & 0.009 \\
\hline Total protein & $5.9(0.1)$ & $6.0(0.08)$ & 0.5 \\
\hline Magnesium (mg/dl) & $1.9(0.05)$ & $1.8(0.02)$ & 0.01 \\
\hline
\end{tabular}

* Mean (standard error)

respectively lower than NBW children (PNS) after adjusting by Body Mass Index, gender and age at assessment.

At 8 years of age, in the crude analysis, for the complete population, there was an overall positive relationship between BMI $\left(\mathrm{kg} / \mathrm{m}^{2}\right)$ and systolic (beta=1.15; 95\% confidence interval 0.33 to 1.96(mmHg) $(\mathrm{p}=0.006))$ and diastolic blood pressure (beta=1.16; 95\% confidence interval 0.55 to 1.77 ( $\mathrm{mmHg})(\mathrm{p}=0.003)$.

Table 5 presents the multiple linear regression analysis between hormonal and metabolic parameters in cord blood at birth and at 8 years of age as independent variables, and blood pressure at 8 years of age as the dependent variable. Results presented are adjusted by gender, gestational age at birth, age and body mass index of the child at the time of blood pressure measurement as well as for the other variables in the regression model, including intrauterine growth category (IUGR vs. NBW).

Independent of the other variables considered, growth hormone at birth and at age 8 years were negatively associated with systolic blood pressure at age 8 years. There is the same tendency with diastolic blood pressure. Adding to this regression model TSH, insulin, prolactin, cholesterol, glucose, albumin and magnesium did not change the observed results (Table 5). The mothers' educational level, used as a proxy indicator for 
Table 3

Hormonal and metabolic characteristics at age 8 years of 64 children. Hospital Universitario Príncipe de Asturias, Alcalá de Henares, Madrid, Spain. 2004

\begin{tabular}{|c|c|c|c|}
\hline Parameter & $\begin{array}{l}\text { Intrauterine growth restriction } \\
\qquad(\mathrm{N}=27)\end{array}$ & $\begin{array}{l}\text { Normal birth weight } \\
\qquad(\mathrm{N}=37)\end{array}$ & $\mathbf{p}$ \\
\hline Growth hormone (ng/ml) & $1.2(0.6)^{*}$ & $0.9(0.4)$ & 0.6 \\
\hline Insulin-like growth factor I (ng/ml) & $184.1(16.3)$ & $196.6(17.7)$ & 0.6 \\
\hline Cortisol (ug/dl) & $16.5(1.2)$ & $14.7(1.4)$ & 0.3 \\
\hline Insulin (U/Mi) & $13.2(2.5)$ & $11.7(1.9)$ & 0.6 \\
\hline Thyroid stimulating hormone(U/ml) & $2.9(0.2)$ & $2.8(0.2)$ & 0.8 \\
\hline Prolactin (ng/ml) & $7.4(0.6)$ & $10.9(2.2)$ & 0.1 \\
\hline Glucose (mg/dl) & $85.3(1.5)$ & $88.6(1.5)$ & 0.1 \\
\hline Cholesterol (mg/dl) & $169.6(5.6)$ & $168.3(6.7)$ & 0.8 \\
\hline Triglycerides (mg/dl) & $73.8(9.2)$ & $75.8(9.2)$ & 0.8 \\
\hline Total protein (g/dl) & $7.4(0.07)$ & $7.3(0.08)$ & 0.4 \\
\hline Magnesium (mg/dl) & $1.9(0.06)$ & $1.7(0.09)$ & 0.1 \\
\hline
\end{tabular}

* Mean (standard error)

Table 4

Clinical characteristics at age 8 years of 64 children. Hospital Universitario Príncipe de Asturias, Alcalá de Henares, Madrid, Spain. 2004

\begin{tabular}{lccc}
\hline \multicolumn{1}{c}{ Parameter } & $\begin{array}{c}\text { Intrauterine growth restriction } \\
(\mathbf{N = 2 7 )}\end{array}$ & $\begin{array}{c}\text { Normal birth weight } \\
(\mathbf{N}=\mathbf{3 7})\end{array}$ & $\mathbf{p}$ \\
\hline Age (years) & & & \\
Weight $(\mathrm{kg})$ & $8.0(1.05)^{*}$ & $8.4(1.04)$ & 0.2 \\
Height $(\mathrm{cm})$ & $28.2(6.67)$ & $31.7(9.75)$ & 0.1 \\
Body mass index $\left(\mathrm{kg} / \mathrm{m}^{2}\right)$ & 128.9 & 133.9 & 0.04 \\
Systolic blood pressure $(\mathrm{mmHg})$ & $17.1(3.13)$ & $17.6(3.28)$ & 0.5 \\
Diastolic blood pressure $(\mathrm{mmHg})$ & $87.2(11.95)$ & $90.9(10.04)$ & 0.1 \\
\hline
\end{tabular}

* Mean (standard deviation)

socioeconomic status, did not modify these relationships either.

\section{DISCUSSION}

We have prospectively studied a cohort, from pregnancy to childhood, with a priori defined objectives, using biochemical indicators of fetal growth and nutritional status specifically collected for this study. As was expected the perinatal characteristics of the newborns were according with the clinical status of the groups
(Table 1) and the body mass index was correlated with both systolic and diastolic blood pressure $(\mathrm{p}=0.003)$. The diagnosis of IUGR was made by both ultrasound examinations during pregnancy and birthweight. The small sample size of the original population, as well as that of the follow-up cohort, is a limitation but the response rate of $84 \%$ is very adequate within the expected rate for follow-up studies in children and adolescents ${ }^{7}$. Although we followed presently recommended techniques for systolic and diastolic blood pressure measurement in children ${ }^{4}$, the single measurement of blood pressure is also a limitation because longitudinal blood pressure recordings better 
Table 5

Multiple regression analysis of the association between biochemical indicators and blood pressure. Hospital Universitario Príncipe de Asturias, Alcalá de Henares, Madrid, Spain

\begin{tabular}{lcc}
\hline \multicolumn{1}{c}{ Independent variable } & Systolic blood pressure & Diastolic blood pressure \\
\hline At birth & Regression coefficients & Regression coefficients \\
Growth hormone $(\mathrm{ng} / \mathrm{ml})$ & $-0.143^{*}(-0.356$ to 0.069$)$ & $-0.078(-0.244$ to 0.088$)$ \\
\hline IGF1 $(\mathrm{mU} / \mathrm{ml})$ & $-0.401(-8.375$ to 7.573$)$ & $2.598(-3.642$ to 8.838$)$ \\
Cortisol $(\mathrm{ug} / \mathrm{dl})$ & $0.145(-0.164$ to 0.455$)$ & $0.137(-0.105$ to 0.379$)$ \\
\hline Insulin $(\mathrm{uU} / \mathrm{ml})$ & $-0.041(-0.682$ to 0.6$)$ & $-0.133(-0.635$ to 0.369$)$ \\
TSH $(\mathrm{uU} / \mathrm{ml})$ & $0.055(-0.19$ to 0.301$)$ & $-0.071(-0.264$ to 0.121$)$ \\
Prolactin $(\mathrm{ng} / \mathrm{ml})$ & $0.005(-0.036$ to 0.046$)$ & $-0.0004(-0.032$ to 0.033$)$ \\
At 8 years of age & & \\
Growth hormone $(\mathrm{ng} / \mathrm{ml})$ & $-1.076(-2.271$ to 0.12$)$ & $-0.488(-1.423$ to 0.448$)$ \\
IGF1 $(\mathrm{ng} / \mathrm{ml})$ & $-0.013(-0.051$ to 0.025$)$ & $-0.029^{+}(-0.059$ to 0.001$)$ \\
Cortisol $(\mathrm{ug} / \mathrm{dl})$ & $0.09(0.322$ to 0.502$)$ & $0.088(-0.234$ to 0.411$)$ \\
Insulin $(\mathrm{uU} / \mathrm{ml})$ & $0.148(-0.124$ to 0.421$)$ & $0.096(-0.116$ to 0.309$)$ \\
\hline TSH $(\mathrm{uU} / \mathrm{ml})$ & $1.863(-1.023$ to 4.479$)$ & $-0.777(-1.482$ to 3.036$)$ \\
Prolactin $(\mathrm{ng} / \mathrm{ml})$ & $-0.186(-0.501$ to 0.13$)$ & $-0.276+(-0.523$ to -0.029$)$ \\
\hline
\end{tabular}

There were 27 intrauterine growth restricted and 37 normal birth weight newborns/children pairs. All regression coefficients were adjusted by gender, gestational age at birth, BMI at 8 years and IUGR/NBW category

* Regression coefficients and 95\% confidence interval in mmHg. $+p=0.05$

represent the true blood pressure level of a child. Unfortunately, placental weight was not available, limiting the possibility of exploring the fetal-placental ratio/blood pressure relationship.

This study presents evidence that serum growth hormone (GH) at birth and at 8 years were negatively associated with systolic blood pressure during childhood independently of the gestational age, gender, age, IUGR/ NBW status, and BMI at the time of blood pressure assessment. This evidence supports the suggestion ${ }^{8}$ that the fetal activation of the hypothalamic-pituitary axis and its long-term effect is related to the programming of cardiovascular development and blood pressure during childhood.

Disturbances in the GH/insulin-like growth factor I axis are recognized as related to post natal growth failure among IUGR infants ${ }^{9}$ and their influence during growth hormone treatment among IUGR infants ${ }^{10}$. However, these disturbances are not always consistent in the literature, perhaps due to the molecular heterogeneity of $\mathrm{GH}$ and levels of bioinactive but immunologically active GH molecules.
There are several reports documenting lower mean estimated secretion rates of $\mathrm{GH}$ in prepubertal short children born IUGR ${ }^{11}$, while others failed to demonstrate differences in urinary GH by patterns of catch-up growth among IUGR infants ${ }^{12}$. Furthermore, the relationship between GH and IGF-I is also influenced by race and gender ${ }^{13}$. An increased proportion of circulating non-22-kilodalton GH is reported in short children ${ }^{14}$ while children 2 to 5 years born IUGR were found to have high basal GH levels ${ }^{11}$. Finally, a non statistical significant negative relationship was observed between urinary GH and blood pressure at 9 years of age ${ }^{15}$. It is important to point out that all this evidence is related to hormonal values during childhood, while our paper presents data on hormonal values at birth and at the time of blood pressure measure before puberty.

The mechanisms responsible for the negative association between growth hormone at birth and blood pressure during childhood are unclear at this point. The growth hormone increase among IUGR infants can be seen as a response to foetal growth alterations most likely unrelated to IGF-I. In this regard, the observed 
negative association between growth hormone and blood pressure at age 8 could be seen as a chronic adaptation to a growth deficit becoming a risk factor for adult diseases particularly among short children. Interestingly, the higher GH levels at birth among IUGR children are not sufficient for a growth catch-up during childhood.Furthermore, our results provide empirical support for the suggestion that blood pressure and somatic growth in children are governed by the similar process ${ }^{16}$ which, as we have shown, is initiated during fetal life, and is still present during childhood ${ }^{1}$.

This process would involve hormones with known growth activity in uterus, such as IGF- ${ }^{17}$ or ACTH with effect on blood pressure increase ${ }^{18}$. It is possible that intrauterine hormonal, nutritional or organ growth alterations can stimulate in uterus, the growth hormone -IGFI axis predisposing some newborns to higher blood pressure when confronted with rapid growth during childhood. This could be the case of a subgroup of IUGR infants with higher levels of growth hormone at birth $^{3}$ or those with high response to growth hormonereleasing hormone ${ }^{19}$. It is clear that the development of the cardiovascular system (antenatal and postnatal) as well as the regulation of blood pressure up to adulthood is controlled by several interrelated mechanisms ${ }^{20}$. The evidence presented here represents one of such mechanisms complementing others, nutritional or environmental, which are yet to be disentangled. We conclude that the alterations on blood pressure can begin in fetal life were levels of GH could have an important role.

\section{REFERENCES}

1. Cheung YB, Low L, Osmond C, Barker D, Karlberg J. Fetal growth and early postnatal growth are related to blood pressure in adults. Hypertension. 2000; 36: 795-800.

2. Vehaskari VM, Aviles DH, Manning J. Prenatal programming of adult hypertension in the rat. Kidney Int. 2001; 59: 238-45.

3. Nieto-Díaz A, Villar J, Matorras-Weinig R, Valenzuela-Ruiz $\mathrm{P}$. Intrauterine growth retardation at term: association between anthropometric and endocrine parameters. Acta Obstet Gynecol Scand. 1996; 75: 127-31.

4. National High Blood Pressure Education Program Working Group on Hypertension Control in Children and Adolescents: Update on the 1987 Task Force. Report on high blood pressure in children and adolescents. A Working Group from the National High Blood Pressure Education Program. Pediatrics. 1996; 98: 649-58.
5. Hashida S, Nakawaga K, Ishikawa E, Ohtaki S. Basal levels of human growth hormone (GH) in normal serum. Clin Chem Acta. 1985; 1: 85-6.

6. Wilke TJ, Eastment HT. Discriminative ability of tests for free and total thyroid hormones in diagnosing thyroid disease. Clin Chem. 1986; 32: 1746-50.

7. Salazar J, Daly K, Scott Giebink G, Lindgen B, Liebeler C, Melond M, et al. Low cord blood pneumococcal immunoglobulin G (lgG) antibodies predict early onset acute otitis media in infancy. Am J Epidemiol. 1997; 145: 1048-56.

8. Fall CH, Pandit AN, Law CM. Size at birth and plasma insulinlike growth factor-I concentrations. Arch Dis Childhood. 1995; 73: 287-93.

9. Sas T, Mulder P, Hokken-Koelega A. Body composition, blood pressure, and lipid metabolism before and during longterm growth hormone $(\mathrm{GH})$ treatment in children with short stature born small for gestational age either with or without $\mathrm{GH}$ deficiency. J Clin Endocrinol Metab. 2000; 85: 3786-92.

10. Boguszewski M, Jansson C, Rosberg S, Albertsson-Wikland K. Changes in serum insulin-like growth factor I (IGF-I) and IGF-binding protein-3 levels during growth hormone treatment in prepubertal short children born small for gestational age. $J$ Clin Endocrinol Metab. 1996; 81: 3902-8.

11. Albertsson-Wikland K, Boguszewski M, Karlberg J. Children born small-for-gestational age: postnatal growth and hormonal status. Horm Res. 1998; 49 Suppl 2: 7-13.

12. García H, Henriquez C, Ugarte F, Fernández E. GH-IGF axis during catch up growth in small for gestational age (SGA) infants. J Pediatr Endocrinol Metab. 1996; 9: 561-7.

13. Xiaozhang J, Srinivasan SR, Dalferes E, Berenson G. Plasma insulin-like growth factor 1 distribution and its relatin to blood pressure in adolescents. Am J Hypertens. 1997; 10: 714-9.

14. Boguszewski CL, Jansson C, Boguszewski MCS, Rosberg S. Increased proportion of circulating non-22-kilodalton growth hormone isoforms in short children: a possible mechanism for growth failure. J Clin Endocrinol Metab. 1997; 82: 2944-9.

15. Fall CHD, Clark PM. Urinary GH and IGF-I excretion in nine year-old children: relation to sex, current size and size at birth. Clin Endocrinol. 2000; 53: 69-76.

16. Lever AF, Harrap SB. Essential hypertension: a disorder of growth with origins in childhood? J Hypertens. 1992; 10: 10120.

17. Guevara-Aguirre J. Insulin-like growth factor I - An important intrauterine growth factor. N Engl J Med. 1996; 335: 1389-91.

18. Scoggins BA, Denton DA, Whitworth JA, Coghlan JD. ACTH dependent hypertension. Clin Exp Hypertens (A). 1984; 6: 599646.

19. Job JC, Chatelain P, Rochiccioli P, Ponte C, Olivier M, Sagmerd L. Growth hormone response to a bolus injection of 1-44 growth-hormone-releasing hormone in very short children with intrauterine onset of growth failure. Horm Res. 1990; 33: 161-5.

20. Maulik D, Frances Evans J, Ragolia L. Fetal growth restriction: pathogenic mechanisms. Clin Obstet Gynecol. 2006; 49: 21927. 